\title{
Double mutation of cell wall proteins CspB and PBP1a increases secretion of the antibody Fab fragment from Corynebacterium glutamicum
}

Yoshihiko Matsuda ${ }^{1,2}$, Hiroshi Itaya ${ }^{1}$, Yuki Kitahara' ${ }^{2}$, Natalia Maria Theresia ${ }^{2}$, Ekaterina Aleksandrovna Kutukova ${ }^{3}$, Yurgis Antanas Vladovich Yomantas ${ }^{3}$, Masayo Date ${ }^{1}$, Yoshimi Kikuchi ${ }^{1}$ and Masaaki Wachi ${ }^{2 *}$

\begin{abstract}
Background: Among other advantages, recombinant antibody-binding fragments (Fabs) hold great clinical and commercial potential, owing to their efficient tissue penetration compared to that of full-length lgGs. Although production of recombinant Fab using microbial expression systems has been reported, yields of active Fab have not been satisfactory. We recently developed the Corynebacterium glutamicum protein expression system (CORYNEX ${ }^{\circledR}$ ) and demonstrated improved yield and purity for some applications, although the system has not been applied to Fab production.

Results: The Fab fragment of human anti-HER2 was successfully secreted by the CORYNEX ${ }^{\circledR}$ system using the conventional C. glutamicum strain YDK010, but the productivity was very low. To improve the secretion efficiency, we investigated the effects of deleting cell wall-related genes. Fab secretion was increased 5.2 times by deletion of pbp1a, encoding one of the penicillin-binding proteins (PBP1a), mediating cell wall peptidoglycan (PG) synthesis. However, this $\triangle$ pbp1a mutation did not improve Fab secretion in the wild-type ATCC13869 strain. Because YDK010 carries a mutation in the cspB gene encoding a surface (S)-layer protein, we evaluated the effect of $\triangle \operatorname{cspB}$ mutation on Fab secretion from ATCC13869. The $\triangle$ pbp1a mutation showed a positive effect on Fab secretion only in combination with the $\triangle \mathrm{cspB}$ mutation. The $\triangle \mathrm{cspB} \triangle \mathrm{pbp} 1$ a double mutant showed much greater sensitivity to lysozyme than either single mutant or the wild-type strain, suggesting that these mutations reduced cell wall resistance to protein secretion.
\end{abstract}

Conclusion: There are at least two crucial permeability barriers to Fab secretion in the cell surface structure of C. glutamicum, the PG layer, and the S-layer. The $\triangle \operatorname{cspB} \triangle \mathrm{pbp} 1$ a double mutant allows efficient Fab production using the CORYNEX ${ }^{\circledR}$ system.

Keywords: CORYNEX ${ }^{\circledast}$, Corynebacterium glutamicum, Protein secretion, Fab fragment, CspB, PBP1a

\section{Background}

Recombinant antibody technologies can generate specialized whole antibodies or fragments with a myriad of potential therapeutic, diagnostic, and research applications [1]. Antibody fragments are particularly promising for clinical application because their ability to penetrate tumor cells is higher than full-length IgGs [2]. The fragment antigen-binding ( $\mathrm{Fab}$ ) molecule contains a fragmented

\footnotetext{
* Correspondence: mwachi@bio.titech.ac.jp

${ }^{2}$ Department of Bioengineering, Tokyo Institute of Technology, 4259

Nagatsuta, Midori-ku, Yokohama 226-8501, Japan

Full list of author information is available at the end of the article
}

heavy chain $(\mathrm{HC})$ composed of the variable $\left(\mathrm{V}_{\mathrm{H}}\right)$ and the first constant $\left(\mathrm{C}_{\mathrm{H} 1}\right)$ domains and a light chain (LC) composed of the light variable $\left(V_{L}\right)$ and constant $\left(C_{L}\right)$ domains. Production of recombinant Fab using microbial expression systems has been reported for several species, including Escherichia coli [3-8], Pichia pastoris [9-12], and Saccharomyces cerevisiae [13], but yields of active Fab have not been satisfactory.

Corynebacterium glutamicum is a Gram-positive, nonpathogenic soil bacterium $[14,15]$ that has been used for industrial-scale production of amino acids such as glutamate and lysine for several decades [16,17]. C. glutamicum 
produces only small amounts of endogenous extracellular proteins compared with many other bacteria commonly used for protein production, a great advantage for protein purification. Thus, C. glutamicum is one of the most accessible and convenient bacterial species for biotechnology, but has not been used extensively for industrial production of proteins. We recently demonstrated that many heterologous proteins can be efficiently secreted in active form by the C. glutamicum ATCC13869 strain. Using a strong $\operatorname{csp} B$ promoter and signal peptides derived from a corynebacterial cell surface protein and the Escherichia coli twin-arginine translocation pathway, C. glutamicum ATCC13869 exhibited great potential as a host for industrial-scale production of recombinant proteins [18-24]. This protein expression system has been awarded trademark registration as CORYNEX'.

Corynebacterium glutamicum has a thick cell wall composed of two layers. The inner layer consists mainly of peptidoglycan (PG) and the outer layer mainly of mycolic acid. The presence of the outer layer may confer resistance against lytic enzymes, such as egg white lysozyme that catalyze hydrolysis of the $\beta-1,4$ glycosidic bond between the $\mathrm{N}$-acetylglucosamine and $\mathrm{N}$-acetylmuramic acid of PG [25], although this bacterium belongs to the Grampositive category. This resistance is probably due to the function of the outer layer as a protein permeability barrier [26-29].

PG is synthesized on the outer surface of the cytoplasmic membrane by enzymes that bind to and are inhibited by $\beta$-lactam-type antibiotics such as penicillin (so that these enzymes are classified as penicillin-binding proteins, PBPs). In general, PBPs are membrane-bound proteins essential for cell wall synthesis by bacteria. They are classified into two types, high-molecular-weight PBPs (HMW-PBPs) and low-molecular-weight PBPs (LMWPBPs). Further, HMW-PBPs are classified into class A HMW-PBPs having both a transpeptidase activity domain for crosslinking PG moieties and a transglycosylase activity domain for forming a polysaccharide chain, and class B HMW-PBPs having only a transpeptidase activity domain [30]. It is known that the class A HMW-PBPs of C. glutamicum are responsible for cell elongation, whereas the class B HMW-PBPs are responsible for formation of PG of septal walls at the time of cell division [30,31]. LMWPBPs have D,D-carboxypeptidase activity and/or endopeptidase activity.

Several C. glutamicum strains have a surface (S)-layer outside the normal cell wall. The S-layer of many bacteria consists of a single protein assembled in two-dimensional paracrystalline arrays. The protein CspB (also called PS2) has been identified as a major secreted protein of several C. glutamicum strains [32,33] and forms the S-layer [34] in this species. Because of its location, the S-layer is generally involved in interactions between the bacterial cell and its environment. The S-layers of several pathogenic bacteria have been reported to act as virulence factors by conferring resistance to bactericidal activity $[35,36]$ and by adhering to the extracellular matrix proteins of the host [37]. Furthermore, the S-layer can serve as a molecular sieve and act to stabilize the bacterial cell envelope of both pathogenic and non-pathogenic bacteria [38].

In the present study, we attempted to produce recombinant Fab using the C. glutamicum protein expression system CORYNEX', but productivity was extremely low. We screened for mutations affecting the efficiency of Fab secretion and found that mutations in certain cell wall-related proteins enhanced Fab secretion, possibly by removing a physical and chemical barrier to secretion. This finding suggests that cell wall structures form a bottleneck for efficient recombinant Fab production in this expression system. The improved CORYNEX ${ }^{\bullet}$ system may enable industrial-scale Fab production.

\section{Results}

\section{Secretion of antibody Fab fragments by C. glutamicum YDK010}

Secretion of the $\mathrm{Fab}(\mathrm{H}+\mathrm{L})$ fragment of the anti-HER2 antibody "trastuzumab", used for targeted therapy of HER2 $^{+}$breast cancer, was first assessed in the YDK010 strain. Bacteria were transformed with the pPKStrastFabHL plasmid containing HC and LC genes of the Fab region fused with the signal peptide derived from the $\operatorname{csp} A$ gene of $C$. ammoniagenes under the control of the $\operatorname{csp} B$ promoter of C. glutamicum (Figure 1 and Additional file 1: Figure S1). The transformant was then cultured in $4 \mathrm{ml}$ of MMTG medium at $30^{\circ} \mathrm{C}$ for $96 \mathrm{~h}$ and the culture supernatant was analyzed by non-reducing SDS-PAGE and Western blotting with anti-human $\operatorname{IgG}(\mathrm{H}+\mathrm{L})$ antibody. A secreted protein of about $45 \mathrm{kDa}$, corresponding to the molecular weight of $\mathrm{Fab}(\mathrm{H}+\mathrm{L})$, was detected in the culture supernatant (Figure 2). This band was subjected to $\mathrm{N}$-terminal amino acid sequencing, and, as expected, the $\mathrm{N}$-terminal amino acid sequences of both HC (EVQLV) and LC (DIQMT) of the Fab $(\mathrm{H}+\mathrm{L})$ were detected. This result indicated that the signal peptide of CspA fused to

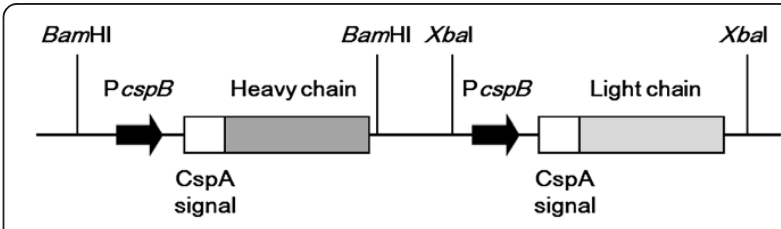

Figure 1 Schematic diagram of the co-expression cassette of $\mathbf{F a b}(\mathbf{H}+\mathbf{L})$ in pPKStrastFabHL. The $\mathrm{Fab}(\mathrm{H}+\mathrm{L})$ expression plasmid pPKStrastFabHL was constructed as described in Methods. The HC and LC genes of the anti-HER2 Fab fragment (shaded bars) fused with the signal peptide of CspA from C. ammoniagenes (open bars) were expressed under control of the cspB promoter from C. glutamicum (thick arrows). 


\section{a SYPROOrange}

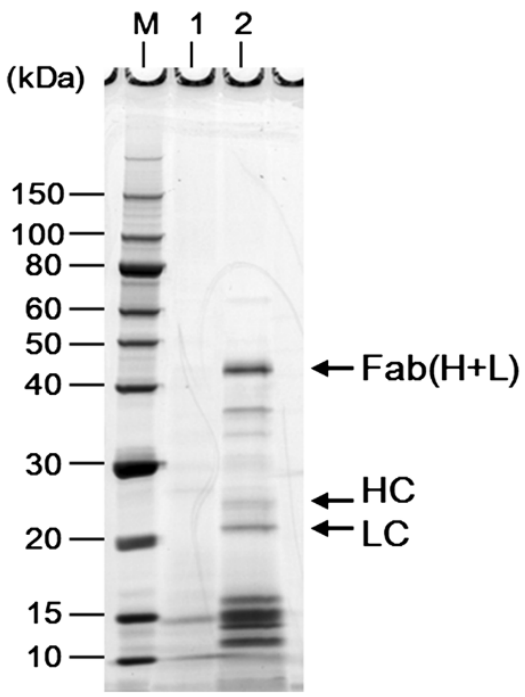

b Anti-lgG

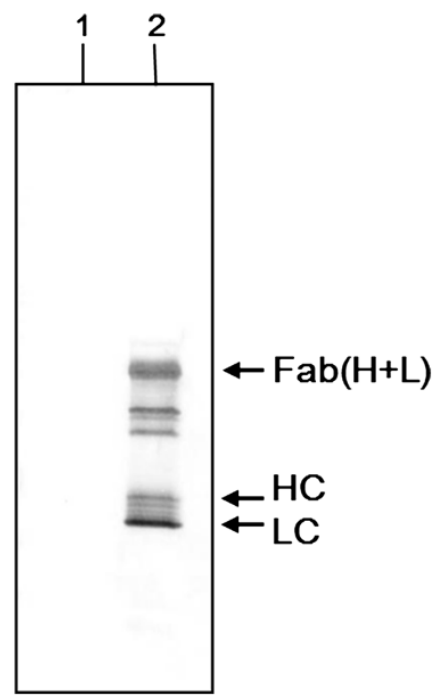

Figure 2 Production of $\mathbf{F a b}(\mathbf{H}+\mathrm{L})$ by $\mathbf{C}$. glutamicum YDK010 carrying pPKStrastFabHL. Supernatant proteins were separated by nonreducing SDS-PAGE. Ten microliters of supernatant mixed with an equal volume of sample buffer were loaded into each lane. (a) A gel stained with SYPRO Orange; (b) Western blot of supernatant proteins probed with anti-human $\lg \mathrm{G}(\mathrm{H}+\mathrm{L})$ antibody. Lane 1, YDK010/pPK4 (empty vector); lane 2, YDK010/pPKStrastFabHL. HC, heavy chain; LC, light chain; M, molecular weight marker.

both HC and LCs had been correctly processed for secretion and that HCs and LCs formed a heterodimer in the culture supernatant. However, accumulation of Fab $(\mathrm{H}+\mathrm{L})$ in the culture supernatant was barely detectable by Coomassie brilliant blue (CBB) staining. The secreted Fab yield was estimated to be approximately $11 \mathrm{mg} / \mathrm{l}$. Protein bands of about 24 and $21 \mathrm{kDa}$, corresponding to the monomeric $\mathrm{HCs}$ and LCs, respectively, were also detected. Indeed, these bands had the expected $\mathrm{N}$ terminal amino acid sequences of $\mathrm{HC}$ and $\mathrm{LC}$. Other minor protein bands at $34-37 \mathrm{kDa}$ were detected and may represent degradation products of $\mathrm{Fab}(\mathrm{H}+\mathrm{L})$.

\section{Enhanced Fab secretion in the pbp1a deletion mutant C. glutamicum YDK010}

To improve the productivity of $\mathrm{Fab}(\mathrm{H}+\mathrm{L})$ by the C. glutamicum YDK010 strain, we first investigated the effects of PBP gene deletion on the Fab secretion, as the PG layer synthesized by PBPs could function as a barrier to Fab secretion. Genome sequence data suggest that C. glutamicum has at least nine PBPs, of which the class A HMWPBPs PBP1a and PBP1b and the class B HMW-PBPs PBP2a, PBP2b, and FtsI (PBP3) are major PG synthases [30]. Of these, only FtsI is essential for C. glutamicum growth [39], whereas the other four HMW-PBPs are dispensable [30]. The LMW-PBPs PBP4, PBP4b, PBP5, and PBP6 were characterized as carboxypeptidases and lactamases on the basis of sequence similarity analysis [30]. In this study, we investigated the effects of deleting each of these nonessential HMW-PBPs on Fab $(\mathrm{H}+\mathrm{L})$ secretion
(Figure 3). Deletion of pbp1a, encoding the class A PBP1a, resulted in approximately 5.2 times higher secretion of $\mathrm{Fab}(\mathrm{H}+\mathrm{L})$ than in the parent strain. In contrast, deletion of $p b p 1 b$ had no effect on $\mathrm{Fab}(\mathrm{H}+\mathrm{L})$ secretion. Similarly, deletion of $p b p 2 a$ and $p b p 2 b$ individually did not increase $\mathrm{Fab}(\mathrm{H}+\mathrm{L})$ secretion (data not shown).

\section{Effect of $\operatorname{csp} B$ mutation on secretion of $\mathrm{Fab}(\mathrm{H}+\mathrm{L})$}

To confirm the positive effect of the $\Delta p b p 1 a$ mutation on $\mathrm{Fab}(\mathrm{H}+\mathrm{L})$ secretion, we evaluated the effect of $\Delta p b p 1 a$ on the wild-type genetic background ATCC13869. Unexpectedly, $\Delta p b p 1 a$ had no effect on $\mathrm{Fab}(\mathrm{H}+\mathrm{L})$ secretion from ATCC13869 (Figure 4, lanes 2 and 4). It is known that during YDK010 strain construction, the $\operatorname{csp} B$ gene encoding the S-layer protein $\mathrm{CspB}$ is deleted [40]. We speculated that the $\operatorname{csp} B$ mutation was somehow involved in allowing $\mathrm{Fab}(\mathrm{H}+\mathrm{L})$ secretion and investigated $\mathrm{Fab}$ secretion in both $\triangle \operatorname{csp} B$ ATCC13869 [41] and the $\triangle c s p B \Delta p b p 1 a$ double mutant ATCC13869. The $\Delta c s p B$ single mutation only slightly affected $\mathrm{Fab}(\mathrm{H}+\mathrm{L})$ secretion (Figure 4, lane 3 ), but the combined $\Delta \operatorname{cspB} \Delta p b p 1 a$ mutation markedly enhanced $\mathrm{Fab}(\mathrm{H}+\mathrm{L})$ secretion compared with both the single mutants and the wild type (Figure 4, lane 5). Thus, $\triangle p b p 1 a$ increases $\mathrm{Fab}(\mathrm{H}+\mathrm{L})$ secretion only in the presence of the $\triangle \operatorname{csp} B$ mutation. In contrast, the $\triangle p b p 1 b$ single mutation and the $\Delta \operatorname{csp} B \triangle p b p 1 b$ double mutation did not affect $\mathrm{Fab}(\mathrm{H}+\mathrm{L})$ secretion (Figure 4, lanes 6 and 7), coherent with the results from the experiment on YDK010 strain. The $\Delta p b p 1 a$ mutation increased Fab secretion 5.2 times $(11.1 \mathrm{mg} / \mathrm{l} \rightarrow 57.6 \mathrm{mg} / \mathrm{l})$ in the 


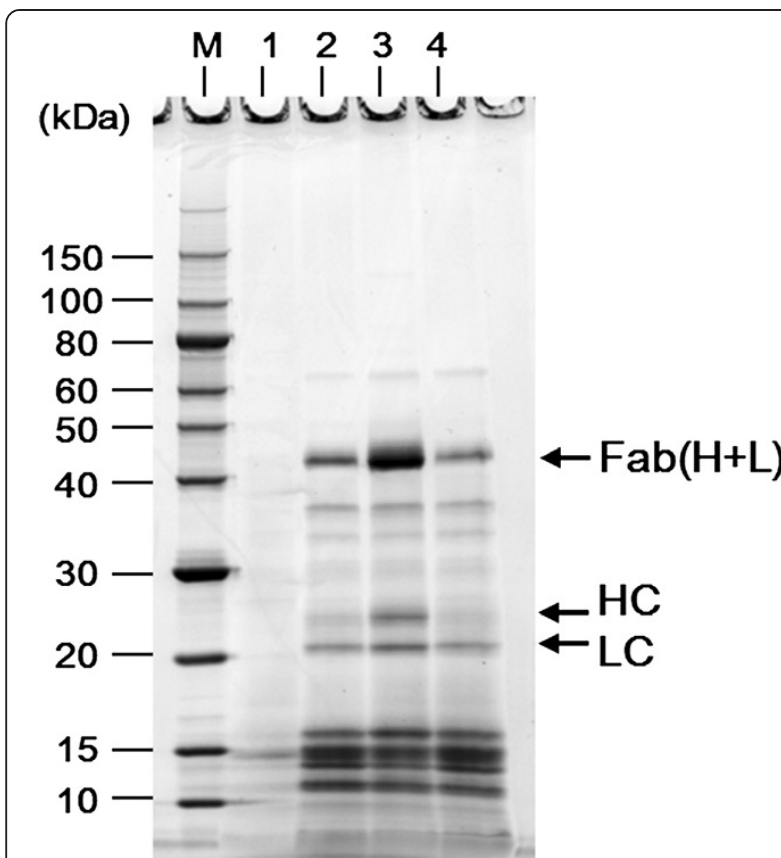

Figure 3 Effect of $\Delta p b p 1 a$ or $\Delta p b p 1 b$ mutation on Fab secretion by C. glutamicum YDK010 strain. Supernatant proteins were separated by non-reducing SDS-PAGE followed by SYPRO Orange staining. Ten microliters of supernatant mixed with an equal volume of sample buffer were loaded into each lane. Lane 1, YDK010/pPK4 (empty vector), lane 2, YDK010/pPKStrastFabHL; lane 3, YDK010 $\Delta \mathrm{pbp1a/pPKStrastFabHL;} \mathrm{lane} \mathrm{4,} \mathrm{YDK010 \Delta pbp1b/}$ pPKStrastFabHL; M, molecular weight marker. Mutation $\triangle$ pbp1a but not $\triangle \mathrm{pbp} 1 \mathrm{~b}$ markedly increases Fab secretion from YDK010. The data shown represent three independent experiments that yielded similar results.

YDK010 strain and 3.9 times $(8.9 \mathrm{mg} / \mathrm{l} \rightarrow 34.9 \mathrm{mg} / \mathrm{l})$ in the ATCC13869 $\triangle \operatorname{csp} B$ strain (Table 1). The YDK010 strain probably carries an unknown mutation that also affects the Fab secretion in the YDK010 background.

\section{Effect of $\operatorname{csp} B$ and $p b p 1 a$ mutations on the lysozyme sensitivity of $C$. glutamicum}

Both CspB and PBP1a are cell wall proteins, and thus, these mutations may affect cell surface integrity. To assess the effects on cell surface integrity, we examined the lysozyme sensitivity of each mutant strain, ATCC13869 WT, $\triangle c s p B, \triangle p b p 1 a, \Delta c s p B \Delta p b p 1 a, \Delta p b p 1 b$, and $\triangle c s p B \Delta p b p 1 b$, by growth assay in LB liquid medium. All strains exhibited similar growth rates under control conditions (Figure 5a). When $25 \mu \mathrm{g} / \mathrm{ml}$ lysozyme was added to exponentially growing cultures, growth of the wild-type strain was not affected, indicating strong lysozyme resistance (Figure $5 b$ ). In contrast, the growth rates of both $\triangle c s p B$ and $\triangle p b p 1 a$ single mutants decreased gradually during lysozyme treatment, resulting in lower final growth yields. The $\triangle c s p B \triangle p b p 1 a$ double mutant showed higher sensitivity to

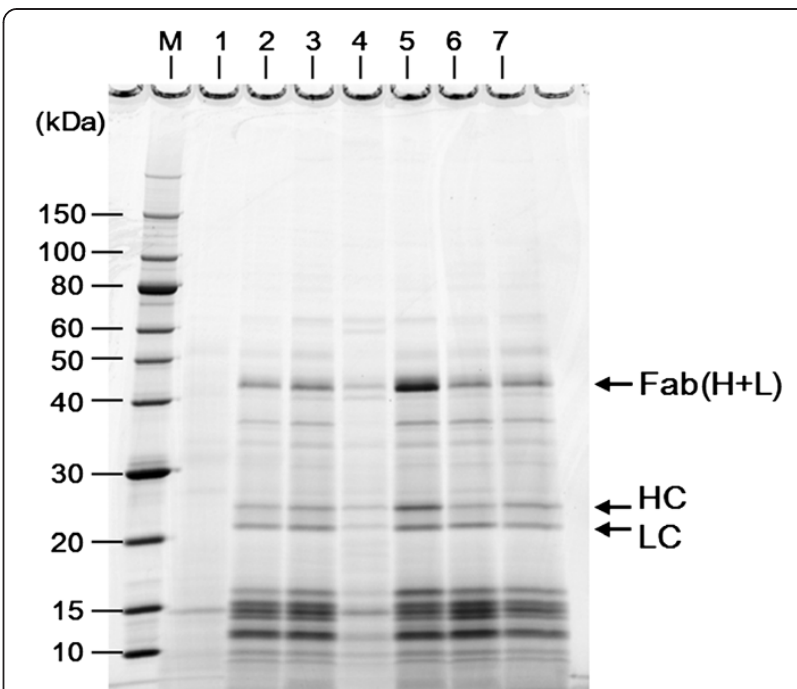

Figure 4 Effects of $\triangle p b p 1 a$ and $\triangle c s p B$ mutations on Fab secretion by $C$. glutamicum wild-type strain ATCC13869. Supernatant proteins were separated by nonreducing SDS-PAGE followed by SYPRO Orange staining. Ten microliters of supernatant mixed with an equal volume of sample buffer were loaded into each lane. Lane 1, ATCC13869/pPK4 (empty vector); lane 2, ATCC13869/ pPKStrastFabHL; lane 3, ATCC13869 $\triangle \mathrm{cspB} /$ pPKStrastFabHL; lane 4, ATCC13869 $\triangle \mathrm{pbp} 1 \mathrm{a} / \mathrm{pPKStrastFabHL;} \mathrm{lane} \mathrm{5,} \mathrm{ATCC13869 \triangle cspB \Delta pbp1a/}$ pPKStrastFabHL; lane 6, ATCC13869 $\triangle$ pbp 1b/pPKStrastFabHL; lane 7, ATCC13869 $\triangle \mathrm{cspB} \triangle \mathrm{pbp} 1 \mathrm{~b} / \mathrm{pPKStrastFabHL;}$ M, molecular weight marker. The $\triangle$ pbpla mutation increases Fab secretion only in the presence of $\Delta \operatorname{cspB}(\Delta \operatorname{csp} B \Delta \mathrm{pbp} 1 \mathrm{a}$ double mutant). The data shown represent three independent experiments that yielded similar results.

lysozyme than did the $\triangle p b p 1 a$ and $\triangle c s p B$ single mutants (Figure $5 \mathrm{~b}$ ). These results suggest that the $\triangle \operatorname{csp} B$ and $\triangle p b p 1 a$ mutations affect cell surface integrity and that the two mutations act together to disrupt cell surface integrity and enhance lysozyme sensitivity. In contrast, the $\Delta p b p 1 b$ single mutant showed higher lysozyme sensitivity than the $\triangle p b p 1 a$ mutant, which was comparable to the $\triangle c s p B \triangle p b p 1 b$ double mutant. However, no

\section{Table 1 Fab production yields by test tube culture}

\begin{tabular}{|c|c|}
\hline Strain & Fab production yield (mg/l) \\
\hline YDK010 & $11.1 \pm 0.3$ \\
\hline YDK010 $\Delta$ pbp1a & $57.6 \pm 2.3$ \\
\hline YDK010 $\Delta$ pbp1b & $10.6 \pm 0.5$ \\
\hline ATCC13869 & $6.4 \pm 0.4$ \\
\hline ATCC13869 $\triangle \mathrm{cspB}$ & $8.9 \pm 0.8$ \\
\hline ATCC13869 $\Delta$ pbp1a & $2.2 \pm 0.4$ \\
\hline ATCC13869 $\triangle$ cspB $\triangle$ pbp1a & $34.9 \pm 1.8$ \\
\hline ATCC13869 $\triangle \mathrm{pbp} 1 \mathrm{~b}$ & $8.1 \pm 1.1$ \\
\hline ATCC13869 $\triangle \mathrm{cspB} \triangle \mathrm{pbp} 1 \mathrm{~b}$ & $7.9 \pm 1.3$ \\
\hline
\end{tabular}

The amount of secreted Fab in culture supernatant was quantified as described in Methods. Yields represent the average of measurements from three separate test tube cultures. 


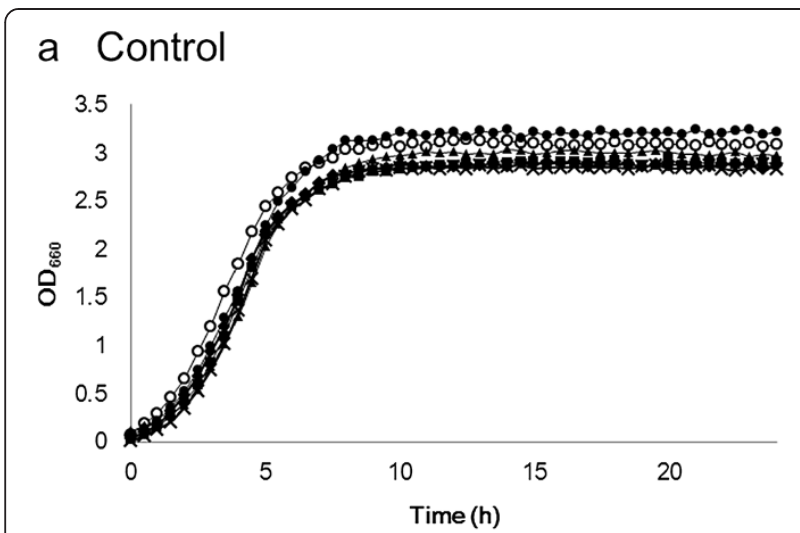

b Lysozyme $25 \mu \mathrm{g} / \mathrm{ml}$

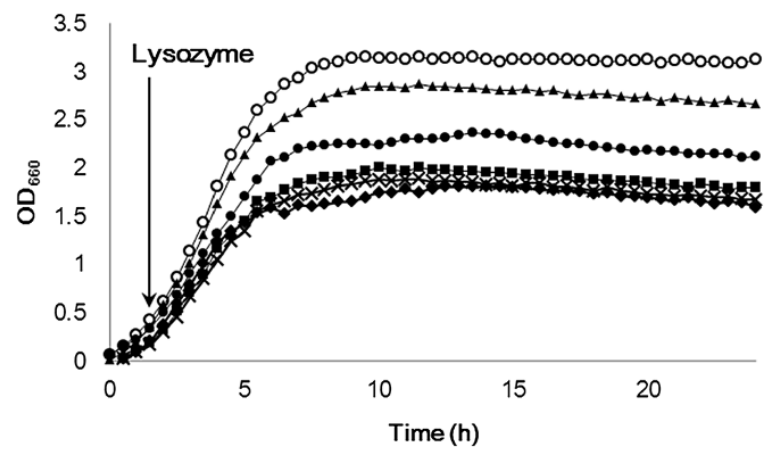

Figure $\mathbf{5}$ Lysozyme sensitivity of $C$. glutamicum strains. (a) C. glutamicum wild-type strain ATCC13869 (open circle), ATCC13869 $\triangle$ pbpla (closed circle), ATCC13869 $\triangle$ cspB (closed triangle), ATCC13869 $\triangle \mathrm{cspB} \triangle \mathrm{pbp} 1 \mathrm{a}$ (closed diamond), ATCC13869 $\triangle \mathrm{pbp} 1 \mathrm{~b}$ (closed square), and ATCC13869 $\triangle \mathrm{cspB} \triangle \mathrm{pbp} 1 \mathrm{~b}(\mathrm{X})$ were incubated in LB medium at $30^{\circ} \mathrm{C}$. (b) Lysozyme (final concentration $25 \mu \mathrm{g} / \mathrm{ml}$ ) was added to the cultures at the time indicated by an arrow. Growth was monitored by measuring $\mathrm{OD}_{660}$. The $\Delta \mathrm{cspB} \Delta \mathrm{pbp} 1 \mathrm{a}$ double mutation considerably increased lysozyme sensitivity compared with either mutation alone or the wild-type strain. The $\Delta p b p 1 b$ mutation showed higher lysozyme sensitivity than $\triangle$ pbpla mutation, but had no synergistic effect with $\Delta \mathrm{cspB}$ mutation.

synergistic effect was observed between $\triangle \operatorname{csp} B$ and $\Delta p b p 1 b$ mutations.

Antigen-binding activity of Fab secreted by C. glutamicum To determine whether the secreted Fab has a correct antigen-binding activity, it was partially purified from culture supernatant by protein $G$ affinity column, and binding activity to its antigen (human HER2/ErbB2) was evaluated by surface plasmon resonance assay as described in Methods. As shown in Figure 6, the Fab secreted by C. glutamicum had binding affinity to the antigen. The dissociation constant $\left(K_{\mathrm{D}}\right)$ value of this partially purified Fab was calculated to be $0.36 \mathrm{nM}$, a value comparable to that in a previous report by Khalili, et al. [42]. This confirmed that the secreted $\mathrm{HC}$ and $\mathrm{LC}$ assembled each other and formed a complete Fab structure in the supernatant.

\section{Discussion}

In this study, we attempted to produce the clinically important antibody Fab fragment, a heterodimeric molecule containing an intermolecular disulfide bond, using the CORYNEX ${ }^{\circ}$ system. As shown in Figure 2, the recombinant $\mathrm{Fab}(\mathrm{H}+\mathrm{L})$ was secreted into the culture medium by the industrial strain YDK010, in addition to the monomeric $\mathrm{HC}$ and LC. Sequencing of the Nterminal amino acids revealed that the signal peptide derived from $C$. ammoniagenes CspA was properly cleaved during secretion. It was also shown that an intermolecular disulfide bond was formed between $\mathrm{HC}$ and LC. The secreted and partially purified Fab showed high binding activity to its antigen HER2/ ErbB2 (Figure 6). This is the first Fab expression experiment performed in C. glutamicum by the conventional CORYNEX ${ }^{\circ}$ system using the $\operatorname{csp} B$ promoter and the Sec-dependent CspA signal peptide. Recently, secretion of antibody single-chain variable fragment $(\mathrm{scFv})$ in C. glutamicum was also reported [43-45]. Yim et al. reported the secretion of $\mathrm{scFv}$ in the C. glutamicum ATCC13032 strain, with approximately $18 \mathrm{mg} / \mathrm{l}$ in flask cultivation and $68 \mathrm{mg} / \mathrm{l}$ in a $5-\mathrm{L}$ bioreactor, using a fully synthetic $\mathrm{H} 36$ promoter and the Sec-dependent PorB signal peptide [45]. scFv is a monomeric molecule, whereas Fab is a heterodimer containing an intermolecular disulfide bond. The present report thus reveals the ability of C. glutamicum to secrete a recombinant heteromultimeric protein in active form. Production of recombinant antibody fragments using microbial expression systems has also been reported, with yields of several dozen $\mathrm{mg} / \mathrm{l}$ [3-13]. In our study, C. glutamicum showed the ability to secrete recombinant antibody fragment at equal or even higher levels than other expression systems. Moreover, this secretion system has a great advantage for protein purification because C. glutamicum produces only small amounts of endogenous extracellular proteins. However, accumulation of the secreted Fab in the YDK010 strain was still low. To identify the bottleneck in Fab production in C. glutamicum, we investigated the effects of specific cell wall-related genes and succeeded in developing a strain with improved secretion ability by mutating $\operatorname{csp} B$ and pbpla.

We first screened the nonessential PBPs in the industrial strain YDK010 (originally derived from the wild-type ATCC13869 strain) and found that the $\Delta p b p 1 a$ deletion markedly improved Fab secretion (Figure 3). However, this effect was not observed on the wild-type background. Further genetic analysis revealed that a mutation in the $\operatorname{csp} B$ gene was also involved in the improvement of Fab secretion. A reconstituted double mutant $\triangle c s p B \Delta p b p 1 a$ on the wild-type ATCC13869 background, but neither of the constituent mutations alone, showed improved Fab secretion (Figure 4). Both $c s p B$ and $p b p 1 a$ are cell wall-related 


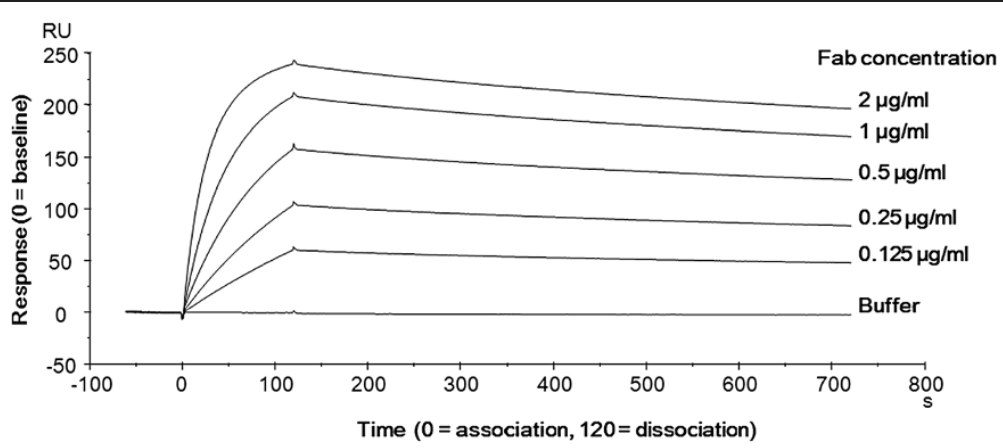

Figure 6 Antigen-binding activity of Fab secreted by C. glutamicum. The secreted Fab was partially purified and assayed for antigen-binding activity by Biacore X100. A CM5 sensor chip immobilized with the extracellular domain of recombinant human HER2/ErbB2 (577 RU) was used to obtain the binding sensorgram of Fab.

genes; PBP1a is involved in PG synthesis, and CspB forms the cell wall S-layer. These results suggest that there are at least two crucial permeability barriers to Fab secretion in the cell surface structure of C. glutamicum.

Because these two genes are both cell wall-related genes, mutations in them may affect the integrity of the cell surface structure. Indeed, a lysozyme sensitivity test supported this idea. Both the $\triangle \operatorname{csp} B$ and $\triangle p b p 1 a$ single mutant strains showed higher lysozyme sensitivity than the wild type, whereas the $\triangle c s p B \triangle p b p 1 a$ double mutant strain showed far greater sensitivity than either single mutant strain (Figure 5). These results indicate that these mutations affect cell surface integrity. Lysozyme sensitivity could be an effective parameter for screening mutations (such as $\operatorname{csp} B$ and $p b p 1 a$ ) that affect, either directly or in combination with other mutations, protein secretion in C. glutamicum.

CspB is a structural protein of the S-layer that forms solid two-dimensional paracrystalline arrays surrounding the entire cell [37]. It is likely that the S-layer interferes with the release of Fab into the extracellular space. Genome sequence data suggest that $C$. glutamicum has at least nine PBPs [30]. Mutants of pbpla and $p b p 1 b$, encoding class A HMW-PBPs, exhibited a similar morphological phenotype [30], although these proteins have distinct binding partners [31]. PBP1a interacts with the cell division protein DivIVA, whereas PBP1b interacts with the morphogenic protein RodA [31]. PBP1b also interacts with $\mathrm{PBP} 2 \mathrm{a}$ and $\mathrm{PBP} 2 \mathrm{~b}$, though PBP1a does not interact directly with any other HMW-PBP [31]. Thus, PBP1a may have a distinct function among HMW-PBPs in C. glutamicum, possibly related to protein secretion.

C. glutamicum has a (coryno)mycolate hydrophobic layer between the PG-arabinogalactan layer and S-layer thought to function as a permeability barrier to antibiotics and host defense molecules [26-29]. It is still unclear how secreted proteins pass through this hydrophobic layer. The mycolate layer is composed of free trehalose mycolates and mycolic acid covalently bound to arabinogalactan, which is in turn attached to the PG layer [28,29]. Loss of PBP1a may affect formation of the mycolate layer by modifying the PG-arabinogalactan layer.

We also examined the secretion of proteins other than Fab, but the $\triangle c s p B \Delta p b p 1 a$ double mutation was only effective for Fab as far as tested (data not shown). This suggests that the bottleneck in protein production is different in each case.

In addition to Fab and constituent monomers, protein bands at approximately $34-37 \mathrm{kDa}$ were detected in the culture supernatant of Fab producer strains. It is clear that these were the degradation products of the secreted Fab, because they were specifically detected by Western blotting with anti-IgG (Figure 2b). Protein bands of approximately $12-16 \mathrm{kDa}$ were also detected by SYPRO Orange staining and did not react with anti-IgG. These could be degradation products of Fab, because they were not detected in the culture supernatant of the strain carrying the empty vector pPK4 (Figure 2a). The protease (s) responsible for Fab degradation are unknown. Identification and deletion of such protease(s) is expected to further improve Fab production by the CORYNEX ${ }^{\circ}$ system.

\section{Conclusions}

We have shown that a combination of $\triangle c s p B$ and $\Delta p b p 1 a$ mutations improves recombinant Fab secretion from $C$. glutamicum, suggesting that there are at least two permeability barriers to Fab secretion in C. glutamicum: the PG layer and the S-layer (Figure 7). Cell wall-associated genes are thus promising targets for further improvement in recombinant protein secretion by C. glutamicum. Moreover, lysozyme sensitivity could be an effective parameter for screening mutations that affect protein secretion.

\section{Methods}

\section{Bacterial strains, plasmids, and culture media}

The bacterial strains and plasmids used in this study are listed in Additional file 2: Table S1. E. coli JM109 was 


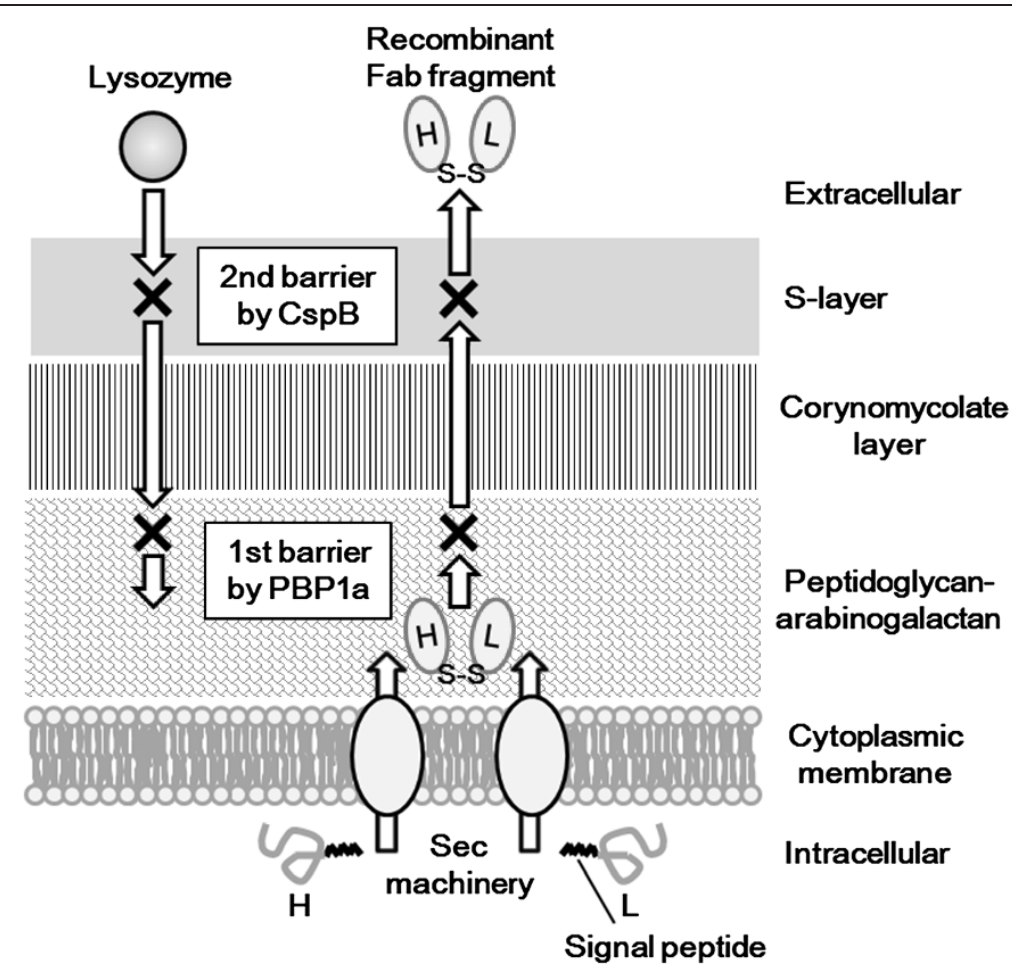

Figure 7 Cell wall-permeability barriers to the recombinant $\mathrm{Fab}(\mathrm{H}+\mathrm{L})$ secretion by $\mathbf{C}$. glutamicum. $\mathrm{HC}$ and $\mathrm{LC}$ of the Fab fragment are secreted through the cytoplasmic membrane by the Sec machinery and form a heterodimer with an intermolecular disulfide bond (S-S) in the extracellular space. There are at least two crucial permeability barriers $(X)$ interrupting Fab secretion; the PG-arabinogalactan layer synthesized by PBP1a and the S-layer composed of CspB. These two structures also function as permeability barriers to lysozyme.

grown in Luria-Bertani (LB) broth [46] and used for plasmid construction. C. glutamicum wild-type strain ATCC13869 and its derivative YDK010, an industrial strain for protein secretion [40], were used. C. glutamicum strains were grown at $30^{\circ} \mathrm{C}$ in modified CM2G medium [18] consisting of $10 \mathrm{~g} / \mathrm{l}$ polypeptone, $10 \mathrm{~g} / \mathrm{l}$ yeast extract, $5 \mathrm{~g} / \mathrm{l}$ glucose, $5 \mathrm{~g} / \mathrm{l} \mathrm{NaCl}$, and $0.2 \mathrm{~g} / \mathrm{l} \mathrm{DL}$ methionine ( $\mathrm{pH}$ 7.2), or modified CMDex medium [41] consisting of $5 \mathrm{~g} / \mathrm{l}$ glucose, $10 \mathrm{~g} / \mathrm{l}$ polypeptone, $10 \mathrm{~g} / \mathrm{l}$ yeast extract, $1 \mathrm{~g} / \mathrm{l} \mathrm{KH}_{2} \mathrm{PO}_{4}, 0.4 \mathrm{~g} / \mathrm{l} \mathrm{MgSO}_{4} \cdot 7 \mathrm{H}_{2} \mathrm{O}, 3 \mathrm{~g} / \mathrm{l}$ urea, $0.01 \mathrm{~g} / \mathrm{l} \mathrm{FeSO}{ }_{4} \cdot 7 \mathrm{H}_{2} \mathrm{O}, 0.01 \mathrm{~g} / \mathrm{l} \mathrm{MnSO}_{4} \cdot 5 \mathrm{H}_{2} \mathrm{O}$, $1.2 \mathrm{~g} / \mathrm{l}$ (as total nitrogen) soybean hydrolysate, and $10 \mu \mathrm{g} / \mathrm{l}$ biotin ( $\mathrm{pH}$ 7.5). For antibody Fab fragment secretion, C. glutamicum strains were cultured in $3 \mathrm{ml}$ of liquid CM2G medium at $30^{\circ} \mathrm{C}$ overnight and $0.2 \mathrm{ml}$ of the cultures were inoculated in $4 \mathrm{ml}$ of modified liquid MMTG medium [18] consisting of $120 \mathrm{~g} / \mathrm{l}$ glucose, $3 \mathrm{~g} / \mathrm{l}$ $\mathrm{MgSO}_{4} \cdot 7 \mathrm{H}_{2} \mathrm{O}, 30 \mathrm{~g} / \mathrm{l}\left(\mathrm{NH}_{4}\right)_{2} \mathrm{SO}_{4}, 1.5 \mathrm{~g} / \mathrm{l} \quad \mathrm{KH}_{2} \mathrm{PO}_{4}$, $0.03 \mathrm{~g} / \mathrm{l} \mathrm{FeSO}{ }_{4} \cdot 7 \mathrm{H}_{2} \mathrm{O}, 0.03 \mathrm{~g} / \mathrm{l} \mathrm{MnSO}_{4} \cdot 5 \mathrm{H}_{2} \mathrm{O}, 0.45 \mathrm{mg} / \mathrm{l}$ thiamine hydrochloride, $0.45 \mathrm{mg} / \mathrm{l}$ biotin, $0.15 \mathrm{mg} / \mathrm{l} \mathrm{DL}$ methionine, $0.2 \mathrm{~g} / \mathrm{l}$ (as total nitrogen) soybean hydrolysate, and $50 \mathrm{~g} / \mathrm{CaCO}_{3}(\mathrm{pH}$ 7.0) in a test tube, and then cultured at $30^{\circ} \mathrm{C}$ for $96 \mathrm{~h}$. Kanamycin $(25 \mu \mathrm{g} / \mathrm{ml})$ was added to the culture medium as required. To prepare agar plates, agar $(20 \mathrm{~g} / \mathrm{l})$ was added to the growth media.

\section{Construction of a plasmid for Fab secretion}

The DNA sequences encoding the variable regions of the HC and LCs of anti-HER2 (GenBank accession numbers, AY513484 and AY513485, respectively) and each constant region were designed by incorporating the $C$. glutamicum codon bias (GenScript, Piscataway, NJ, USA). DNA fragments containing the promoter of $\operatorname{cspB}$ from C. glutamicum and the signal sequence of CspA from $C$. ammoniagenes were fused to the $\mathrm{HC}$ or LC genes by GenScript to produce the tandem expression cassette (Figure 1 and Additional file 1: Figure S1). The synthesized

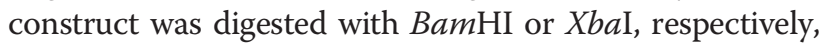
and inserted into the BamHI and XbaI sites of pPK4 [18] to obtain pPKStrastFabHL. The cloned fragments were sequenced to confirm the intended construction.

\section{Protein analysis}

The culture supernatant was obtained by centrifugation and $10 \mu \mathrm{l}$ of supernatant was mixed with an equal 
volume of SDS sample buffer (Bio-Rad, Hercules, CA, USA) without reducing agent. Proteins were separated by $10 \%-20 \%$ gradient polyacrylamide gel electrophoresis (PAGE) as described by Laemmli [47] under non-reducing conditions, and the gels were stained with SYPRO Orange (Life Technologies, Carlsbad, CA, USA). Estimation of Fab production yield was done by quantifying the intensity of protein bands in gels using Multi Gauge software (Fujifilm, Tokyo, Japan). A standard curve was generated using a standard protein solution of known concentration run in the same gel. For determining the $\mathrm{N}$-terminal amino acid sequence, proteins were transferred to a polyvinylidene difluoride (PVDF) membrane by electroblotting after separation by sodium dodecyl sulfate (SDS)-PAGE, and the protein bands were directly applied to a gas-phase protein sequencer (model PSQ; Shimadzu, Kyoto, Japan) equipped with an in-line amino acid analyzer (model RF-550; Shimadzu), as described previously [48]. Western blotting analysis was performed with alkaline phosphatase (AP) conjugated anti-human IgG $(\mathrm{H}+\mathrm{L})$ antibody (Rockland Immunochemicals, Gilbertsville, PA, USA) and an AP conjugate substrate kit (Bio-Rad, Hercules, CA, USA).

\section{Antigen-binding activity analysis of Fab}

Culture supernatant was collected by centrifugation and filtered with a $0.22 \mu \mathrm{m}$ Millex-GV syringe filter unit (Merck Millipore, Billerica, MA, USA). $20 \mathrm{ml}$ of the filtrated supernatant was injected directly onto $1 \mathrm{ml}$ of HiTrap Protein G affinity column (GE Healthcare UK. Ltd., Buckinghamshire, England) which was pre-equilibrated with $20 \mathrm{mM}$ Tris- $\mathrm{HCl}$ (pH 7.5). Subsequently, Fab trapped in the column was eluted with $3 \mathrm{ml}$ of $0.1 \mathrm{M}$ Glycine- $\mathrm{HCl}(\mathrm{pH} 2.7)$, and $20 \mu \mathrm{l}$ of $2 \mathrm{M}$ Tris- $\mathrm{HCl}(\mathrm{pH} 8.5)$ was added immediately to bring to physiological $\mathrm{pH}$. Biacore X100 (GE Healthcare UK. Ltd., Buckinghamshire, England) was used for surface plasmon resonance analysis. The extracellular domain of recombinant human HER2/ ErbB2 (Sino Biological Inc., Beijing, China) was diluted in $10 \mathrm{mM}$ sodium phosphate buffer ( $\mathrm{pH}$ 6.0) and immobilized on a CM5 sensor chip (GE Healthcare UK. Ltd., Buckinghamshire, England) to achieve 577 resonance units (RU) by amine coupling according to the manufacturer's instructions. Various concentrations of samples were injected into the flow cell diluted with HBS-EP buffer (10 mM HEPES $\mathrm{pH}$ 7.4, $150 \mathrm{mM} \mathrm{NaCl}, 3 \mathrm{mM}$ EDTA and 0.005\% surfactant P20). All kinetic measurements were conducted at $25^{\circ} \mathrm{C}$ at a flow rate of $30 \mu \mathrm{l} / \mathrm{min}$ with an association time of $120 \mathrm{~s}$ and dissociation time of $600 \mathrm{~s}$. Chip regeneration was accomplished by exposing the chip to $10 \mathrm{mM}$ Glycine- $\mathrm{HCl}$ (pH 1.5) for 120 s. Data were calculated using Biacore X100 evaluation software (GE Healthcare UK. Ltd., Buckinghamshire, England) by fitting the data to a 1:1 binding model.

\section{Construction of $p b p 1 a$ and $p b p 1 b$ deletion mutants of C. glutamicum}

C. glutamicum disruptants were constructed as described previously [41]. Plasmid pBS5T [49], which carries a temperature-sensitive replication origin and the Bacillus subtilis sacB gene, was used as a suicide vector [50]. To construct a pbp1a disruptant, two successive rounds of PCR were performed. In the first-round, a 1.0-kb upstream region of the pbpla gene was PCR-amplified from ATCC13869 chromosomal DNA template using the primers 5 '-GTCGGATCCGCCCCCCTGAGCCAAATAT 'TC-3' and 5' ${ }^{\prime}$-TTTCTAGCGGAAGAACTGGTTGATGG CGTCGAGCTTTGTCAGAGA-ATTCGTGGT-3', and a $1.0-\mathrm{kb}$ downstream region of the pbp1a gene was PCR-amplified using primers 5'- GTGTCCACCAC GAATTCTCTGACAAAGC-TCGACGCCATCAACCAG 'TTCTTCC-3' and 5'-AGTATCTAGATTCGAGTCG CTT-TTGGTTGGC-3'. Second-round PCRs were performed on the first-round $\mathrm{PCR}$ products using the primers 5'-GTCGGATCCGCCCCCCTGAGCCAAATATTC-3' and $5^{\prime}$ - AGTATCTAGATTCGAGTCGCTTTTGGTT GGC-3'. The amplified fragments were digested with

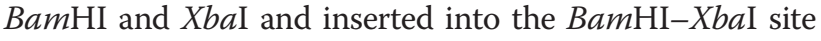
of pBS5T to obtain pBS5T $\Delta$ pbp1a. Similarly, to construct a $p b p 1 b$ disruptant, a 1.3-kb upstream region of the $p b p 1 b$ gene was PCR-amplified from ATCC13869 chromosomal DNA template using the primers 5 '-CGGCGAA CTCAAAAACAGCAT-3' and 5'-GGATAGTCAGCC CCGGCAGGATCCTTTTGCCACTGCTCTTTTTG -3', and a $1.1-\mathrm{kb}$ downstream region of the $p b p 1 b$ gene was PCR-amplified using primers 5'- CAAAAAGAG CAGTGGCAAAAGGATCCTGCCGGGGCTGACTATC$3^{\prime}$ and $5^{\prime}$ - CCAAACAACCCGAAGCTCAAC-3' as firstround PCRs. Second-round PCRs were performed on the first-round PCR products using primers 5'-CGGC GAACTCA-AAAACAGCAT-3' and 5'-CCAAACAACC CGAAGCTCAAC-3'. Amplified fragments were digested with PstI and Sall, and the resulting 2.2-kb fragment was inserted into the PstI-SalI site of pBS5T to give pBS5T $\Delta$ pbp1b. Vector pBS5T $\Delta$ pbp1a or pBS5T $\Delta$ pbp1b was introduced into C. glutamicum by electroporation, and kanamycin-resistant transformants were selected at $34^{\circ} \mathrm{C}$. Because pBS5T does not replicate at $34^{\circ} \mathrm{C}$, only single-crossover chromosomal integrants grew on kanamycin-containing CMDex plates at $34^{\circ} \mathrm{C}$. One of the kanamycin-resistant transformants was grown in CMDex medium without kanamycin overnight, and the cells were spread on sucrose-containing CMDex agar plates $(10 \%$ sucrose). Cells carrying the $s a c B$ gene do not grow in the presence of sucrose, and thus, only cells in which the $s a c B$ gene was excised from the chromosome by a second homologous recombination event grew on the sucrosecontaining plates. The resulting sucrose-resistant recombinants presumably had the wild-type or the deleted 
pbp1a or pbp1b gene, depending on the recombination points. The desired disruptants were selected by PCR. The pbp1a or pbp1b deletion mutants of C. glutamicum were designated as YDK010 $\Delta p b p 1 a$, YDK010 $\Delta p b p 1 b$, ATCC 13869 $\Delta p b p 1 a$, ATCC13869 $\Delta p b p 1 b$, АTCC13869 $\Delta c s p B \Delta p$ $b p 1 a$, and ATCC13869 $\triangle c s p B \triangle p b p 1 b$, respectively.

\section{Lysozyme sensitivity test of $C$. glutamicum}

Lysozyme sensitivities of C. glutamicum ATCC13869, $\triangle c s p B, \triangle p b p 1 a, \Delta c s p B \Delta p b p 1 a, \Delta p b p 1 b$, and $\triangle c s p B \Delta p b p 1 b$ mutants were evaluated by growth assay in LB liquid medium or plate assay, as described previously [51].

\section{Additional files}

Additional file 1: Figure S1. Nucleotide sequence of the co-expression cassette of $\mathrm{Fab}(\mathrm{H}+\mathrm{L})$ in $\mathrm{pPKStrastFabHL}$, with the amino acid sequences given below. The sequence is presented in the $5^{\prime}$ to $3^{\prime}$ direction. The putative ribosome-binding site (RBS), the amino acid sequence of the CspA signal peptide, and restriction enzyme sites are boxed, underlined, and described in lower case, respectively. The sequences of $\mathrm{HC}$ and $\mathrm{LC}$ gene of the anti-HER2 Fab fragment are described in boldface.

Additional file 2: Table S1. Bacterial strains and plasmids used in this study.

\section{Abbreviations \\ AP: Alkaline phosphatase; ATCC: American-type culture collection; CORYNEX: Corynebacterium glutamicum protein expression system; Csp: Cell surface protein; Da: Dalton; Fab: Fragment antigen-binding; HC: Heavy chain; HMW: High molecular weight; IgG: Immunoglobulin G; LC: Light chain; LMW: Low molecular weight; OD: Optical density; PBP: Penicillin-binding protein; PCR: Polymerase chain reaction; PG: Peptidoglycan; \\ PVDF: Polyvinylidene difluoride; RU: Resonance unit; S-layer: Surface layer; scFv: Single-chain variable fragment; SDS-PAGE: Sodium dodecyl sulfate polyacrylamide gel electrophoresis; Strain name/plasmid name: Denotes a plasmid-carrying strain.}

\section{Competing interests}

The authors declare that they have no competing interests.

\section{Authors' contributions}

YM designed and performed the Fab secretion and analyses, constructed the mutant strains, coordinated the work, and drafted the manuscript. HI designed the mutant strains and coordinated the work. YK and NMT performed the lysozyme sensitivity test. EAK and YAVY designed and constructed the mutant strains. MD assayed the antigen-binding activity of Fab. YK and MW supervised the work and reviewed the final manuscript. All authors read and approved the final manuscript.

\section{Acknowledgments}

We thank Dr Chikako Nakai, Dr Tomoko Ohsato and Rie Takeshita for the technical support. We also thank Dr Shintaro Iwatani and all the members of CORYNEX research group of Ajinomoto Co., Inc. for helpful discussion.

\section{Author details}

'Institute for Innovation, Ajinomoto Co., Inc, 1-1 Suzuki-cho, Kawasaki-ku, Kawasaki 210-8681, Japan. ${ }^{2}$ Department of Bioengineering, Tokyo Institute of Technology, 4259 Nagatsuta, Midori-ku, Yokohama 226-8501, Japan.

${ }^{3}$ Ajinomoto-Genetika Research Institute, 1st Dorozhny pr. 1, Moscow 113545, Russia.

Received: 1 October 2013 Accepted: 17 March 2014

Published: 15 April 2014

\section{References}

1. Reichert JM, Rosensweig CJ, Faden LB, Dewitz MC: Monoclonal antibody successes in the clinic. Nat Biotechnol 2005, 23:1073-1078.

2. Holliger P, Hudson PJ: Engineered antibody fragments and the rise of single domains. Nat Biotechnol 2005, 23:1126-1136.

3. Levy R, Weiss R, Chen G, Iverson BL, Georgiou G: Production of correctly folded fab antibody fragment in the cytoplasm of Escherichia coli trxB gor mutants via the coexpression of molecular chaperones. Protein Expr Purif 2001, 23:338-347.

4. Venturi M, Seifert $C$, Hunte $C$ : High level production of functional antibody fab fragments in an oxidizing bacterial cytoplasm. J Mol Biol 2002, 315:1-8.

5. Quintero-Hernandez V, Juarez-Gonzalez VR, Ortiz-Leon M, Sanchez R, Possani LD, Becerril B: The change of the scFv into the Fab format improves the stability and in vivo toxin neutralization capacity of recombinant antibodies. Mol Immunol 2007, 44:1307-1315.

6. Leonard B, Sharma V, Smider V: Co-expression of antibody fab heavy and light chain genes from separate evolved compatible replicons in $E$. coli. $J$ Immunol Methods 2006, 317:56-63.

7. Masri SA, Rast H, Hu WG, Nagata LP, Chau D, Jager S, Mah D: Cloning and expression in $E$. coli of a functional Fab fragment obtained from single human lymphocyte against anthrax toxin. Mol Immunol 2007, 44:2101-2106.

8. Ukkonen K, Veijola J, Vasala A, Neubauer P: Effect of culture medium, host strain and oxygen transfer on recombinant Fab antibody fragment yield and leakage to medium in shaken E. coli cultures. Microb Cell Fact 2013, 12:73.

9. Lange S, Schmitt J, Schmid RD: High-yield expression of the recombinant, atrazine-specific Fab fragment K411B by the methylotrophic yeast Pichia pastoris. J Immunol Methods 2001, 255:103-114.

10. Ning D, Junjian X, Qing Z, Sheng X, Wenyin C, Guirong R, Xunzhang W: Production of recombinant humanized anti-HBsAg Fab fragment from Pichia pastoris by fermentation. J Biochem Mol Biol 2005, 38:294-299.

11. Gasser B, Maurer M, Gach J, Kunert R, Mattanovich D: Engineering of Pichia pastoris for Improved Production of Antibody Fragments. Biotechnol Bioeng 2006, 94:353-361.

12. Burtet RT, Santos-Silva MA, Buss GA, Moraes LM, Maranhaó AQ, Brigido MM: Production of a recombinant Fab in Pichia pastoris from a monocistronic expression vector. J Biochem 2007, 142:665-669.

13. Weaver-Feldhaus JM, Lou J, Coleman JR, Siegel RW, Marks JD, Feldhaus MJ: Yeast mating for combinatorial Fab library generation and surface display. FEBS Lett 2004, 564:24-34.

14. Ikeda M, Nakagawa S: The Corynebacterium glutamicum genome: features and impacts on biotechnological processes. Appl Microbiol Biotechnol 2003, 62:99-109.

15. Kalinowski J, Bathe B, Bartels D, Bischoff N, Bott M, Burkovski A, Dusch N, Eggeling L, Eikmanns BJ, Gaigalat L, Goesmann A, Hartmann M, Huthmacher K, Krämer R, Linke B, McHardy AC, Meyer F, Möckel B, Pfefferle W, Pühler A, Rey DA, Rückert C, Rupp O, Sahm H, Wendisch VF, Wiegräbe I, Tauch A: The complete Corynebacterium glutamicum ATCC 13032 genome sequence and its impact on the production of L-aspartate-derived amino acids and vitamins.J Jiotechnol 2003, 104:5-25

16. Hermann T: Industrial production of amino acids by coryneform bacteria. J Biotechnol 2003, 104:155-172.

17. Krämer R: Secretion of amino acids by bacteria: physiology and mechanism. FEMS Microbiol Rev 1994, 12:75-94.

18. Kikuchi $Y$, Date M, Yokoyama K, Umezawa Y, Matsui H: Secretion of activeform Streptoverticillium mobaraense transglutaminase by Corynebacterium glutamicum: processing of the pro-transglutaminase by a cosecreted subtilisin-like protease from Streptomyces albogriseolus. Appl Environ Microbiol 2003, 69:358-366

19. Date M, Yokoyama K, Umezawa Y, Matsui H, Kikuchi Y: Production of nativetype Streptoverticillium mobaraense transglutaminase in Corynebacterium glutamicum. Appl Environ Microbiol 2003, 69:3011-3014.

20. Date M, Yokoyama K, Umezawa Y, Matsui H, Kikuchi Y: High level expression of Streptomyces mobaraensis transglutaminase in Corynebacterium glutamicum using a chimeric pro-region from Streptomyces cinnamoneus transglutaminase. J Biotechnol 2004, 110:219-226.

21. Date M, Yokoyama K, Umezawa Y, Matsui H, Kikuchi Y: Secretion of human epidermal growth factor by Corynebacterium glutamicum. Lett Appl Microbiol 2006, 42:66-70. 
22. Kikuchi Y, Date M, Itaya H, Matsui K, Wu LF: Functional analysis of the twin-arginine translocation pathway in Corynebacterium glutamicum ATCC 13869. Appl Environ Microbiol 2006, 72:7183-7192.

23. Kikuchi $Y$, Itaya $H$, Date M, Matsui K, Wu LF: Production of Chryseobacterium proteolyticum protein-glutaminase using the twinarginine translocation pathway in Corynebacterium glutamicum. Appl Microbiol Biotechnol 2008, 78:67-74.

24. Kikuchi Y, Itaya H, Date M, Matsui K, Wu LF: TatABC overexpression improves Corynebacterium glutamicum Tat-dependent protein secretion. Appl Environ Microbiol 2009, 75:603-607.

25. Schindler M, Assaf Y, Sharon N, Chipman DM: Mechanism of lysozyme catalysis: role of ground-state strain in subsite $D$ in hen egg-white and human lysozymes. Biochemistry 1977, 16:423-431.

26. Draper $P$ : The outer parts of the mycobacterial envelope as permeability barriers. Front Biosci 1998, 3:D1253-D1261.

27. Jarlier $\mathrm{V}$, Nikaido $\mathrm{H}$ : Permeability barrier to hydrophilic solutes in Mycobacterium chelonei. J Bacteriol 1990, 172:1418-1423.

28. Puech V, Chami M, Lemassu A, Lanéelle MA, Schiffler B, Gounon P, Bayan N, Benz R, Daffé M: Structure of the cell envelope of corynebacteria: importance of the non-covalently bound lipids in the formation of the cell wall permeability barrier and fracture plane. Microbiology 2001, 147:1365-1382.

29. Eggeling L, Sahm H: The cell wall barrier of Corynebacterium glutamicum and amino acid efflux. J Biosci Bioeng 2001, 92:201-213.

30. Valbuena N, Letek M, Ordóñez E, Ayala J, Daniel RA, Gil JA, Mateos LM: Characterization of HMW-PBPs from the rod-shaped actinomycete Corynebacterium glutamicum: peptidoglycan synthesis in cells lacking actin-like cytoskeletal structures. Mol Microbiol 2007, 66:643-657.

31. Letek M, Fiuza M, Ordóñez E, Villadangos AF, Ramos A, Mateos LM, Gil JA: Cell growth and cell division in the rod-shaped actinomycete Corynebacterium glutamicum. Antonie van Leeuwenhoek 2008, 94:99-109.

32. Joliff G, Mathieu L, Hahn V, Bayan N, Duchiron F, Renaud M, Schechter E, Leblon G: Cloning and nucleotide sequence of the csp1 gene encoding PS1, one of the two major secreted proteins of Corynebacterium glutamicum: the deduced N-terminal region of PS1 is similar to the Mycobacterium antigen 85 complex. Mol Microbiol 1992, 6:2349-2362.

33. Hansmeier N, Bartels FW, Ros R, Anselmetti D, Tauch A, Pühler A, Kalinowski J: Classification of hyper-variable Corynebacterium glutamicum surface-layer proteins by sequence analyses and atomic force microscopy. J Biotechnol 2004, 112:177-193.

34. Payret JL, Bayan N, Joliff G, Gulik-Krzywicki T, Mathieu L, Schechter E, Leblon G Characterization of the $\operatorname{csp} B$ gene encoding PS2, an ordered surface-layer protein in Corynebacterium glutamicum. Mol Microbiol 1993, 9:97-109.

35. Blaser MJ, Smith PF, Hopkins JA, Heinzer I, Bryner JH, Wang WL: Pathogenesis of Campylobacter fetus infections: serum resistance associated with high-molecular-weight surface proteins. Infect Dis 1987, 155:696-706.

36. Merino S, Albertí S, Tomás JM: Aeromonas salmonicida resistance to complement-mediated killing. Infect Immun 1994, 62:5483-5490.

37. Schneitz C, Nuotio L, Lounatma K: Adhesion of Lactobacillus acidophilus to avian intestinal epithelial cells mediated by the crystalline bacterial cell surface layer (S-layer). J Appl Bacteriol 1993, 74:290-294.

38. Sála M, Sleytr UB: S-Layer proteins. J Bacteriol 2000, 182:859-868.

39. Valbuena N, Letek M, Ramos A, Ayala J, Nakunst D, Kalinowski J, Mateos LM, Gil JA: Morphological changes and proteome response of Corynebacterium glutamicum to a partial depletion of Ftsl. Microbiology 2006, 152:2491-2503.

40. Kikuchi Y, Date M, Umezawa Y, Yokoyama K, Heima H, Matsui H: Method for the secretion and production protein. Int Pat Cooperat Treaty Pat 2002, WO2002/081694

41. Takeshita $\mathrm{R}$, Ito $\mathrm{H}$, Wachi $\mathrm{M}$ : A role of the $\operatorname{csp} A$ gene encoding a mycolyltransferase in the growth under alkaline conditions of Corynebacterium glutamicum. Biosci Biotechnol Biochem 2010, 74:1617-1623.

42. Khalili H, Godwin A, Choi JW, Lever R, Brocchini S: Comparative binding of disulfide-bridged PEG-Fabs. Bioconjug Chem 2012, 23:2262-2277.

43. An SJ, Yim SS, Jeong KJ: Development of a secretion system for the production of heterologous proteins in Corynebacterium glutamicum using PorB signal peptide. Protein Expr Purif 2013, 89:251-257.
44. Yim SS, An SJ, Kang M, Lee J, Jeong KJ: Isolation of fully synthetic promoters for high-level gene expression in Corynebacterium glutamicum. Biotechnol Bioeng 2013, 110:2959-2971.

45. Yim SS, An SJ, Choi JW, Ryu AJ, Jeong KJ: High-level secretory production of recombinant single-chain variable fragment (scFv) in Corynebacterium glutamicum. Appl Microbiol Biotechnol 2014, 98:273-284.

46. Sambrook J, Fritsch EF, Maniatis T: Molecular Cloning: A Laboratory Manual. Cold Spring Harbor: Cold Spring Harbor Press; 1989.

47. Laemmli UK: Cleavage of structural proteins during the assembly of the head of bacteriophage T4. Nature 1970, 227:680-685.

48. Kikuchi Y, Kojima H, Tanaka T, Takatsuka Y, Kamio Y: Characterization of a second lysine decarboxylase isolated from Escherichia coli. J Bacteriol 1997, 179:4486-4492.

49. Chinen A, Kozlov Yl, Hara Y, Izui H, Yasueda H: Innovative metabolic pathway design for efficient I-glutamate production by suppressing $\mathrm{CO}_{2}$ emission. J Biosci Bioeng 2007, 103:262-269.

50. Quandt J, Hynes MF: Versatile suicide vectors which allow direct selection for gene replacement in gram-negative bacteria. Gene 1993, 127:15-21.

51. Hirasawa T, Wachi M, Nagai K: A mutation in the Corynebacterium glutamicum ItsA gene causes susceptibility to lysozyme, temperaturesensitive growth, and L-glutamate production. J Bacteriol 2000, 182:2696-2701.

doi:10.1186/1475-2859-13-56

Cite this article as: Matsuda et al:: Double mutation of cell wall proteins CspB and PBP1a increases secretion of the antibody Fab fragment from Corynebacterium glutamicum. Microbial Cell Factories 2014 13:56.

\section{Submit your next manuscript to BioMed Central and take full advantage of:}

- Convenient online submission

- Thorough peer review

- No space constraints or color figure charges

- Immediate publication on acceptance

- Inclusion in PubMed, CAS, Scopus and Google Scholar

- Research which is freely available for redistribution 